Military Technical College Kobry Elkobbah, Cairo, Egypt.

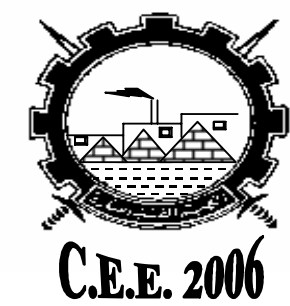

$3^{\text {rd }}$ International Conference

On

Chemical \& Environmental Engineering

\title{
STUDY OF THE COMBUSTION BEHAVIOR OF THE LOW OXYGEN CONTENT COMPOSITE SOLID PROPELLANTS
}

\author{
ABD ELWARETH W. M. *, SHOKRY Sh. A. **, ELAHWANY A. H. *** \\ and SADEK M. A. ****
}

\begin{abstract}
The combustion behavior, flammability limits and ballistic properties, of composite low oxygen content propellants were studied experimentally by using propellant formulations based on hydroxy-terminated polybutadiene pre-polymer (HTPB) / ammonium perchlorate oxidizer (AP). Higher pressures and AP contents as well as smaller AP particle size were found to promote sustained combustion and to increase burning rate. The addition of aluminum powder $(\mathrm{Al})$ as a metallic fuel and copper chromite (CC), burning rate accelerator, caused an increase in the burning rate. A significant increase of burning rate was recorded when $\mathrm{CC}$ added to the aluminized formulations compared with the non-aluminized of the same oxidizer solid loading and particle size.
\end{abstract}

\footnotetext{
* Egyptian Armed Forces.

** Ministry of Military Production.

${ }^{* * *}$ Faculty of Engineering, Cairo University.

**** Higher Technological Institute- $10^{\text {th }}$ of Ramadan.
} 


\section{INTRODUCTION}

Low oxygen content propellants are typically used for ramjet-rocket (ducted-rocket) motors, which also called air-breathing systems. The ramjet-rocket motor consists of two combustion chambers: The low oxygen content propellant is placed in the primary combustor which serves as a gas generator. The combustible, partially burned products generated in this combustor are ejected into a secondary ramjetcombustor and continue to burn with the incoming atmospheric air. A solid fuel ramjet rocket motor configuration is shown in Fig.1 [1, 2].

Low oxygen content propellants can be classified into metal-loaded compositions with high smoke levels, carbon compositions with moderate smoke levels and hydrocarbon-fueled compositions with low smoke levels. Low oxygen content propellants are characterized by low combustion temperature, burning rates in the range of few millimeters per second and low specific impulse [3, 4].

The specific impulse produced from an air breathing system can be double or triple that produced from the conventional solid propellant systems with high oxygen content. The lower the specific impulse of the propellant combustion products efflux from the first chamber the higher the specific impulse produced from the second chamber according to the mixing ratio of combustion products with air, chamber pressure, flight Mach number and air composition at a certain altitude [2].

The aim of the present experimental investigation was to determine the flammability limits and the ballistic parameters of such low oxygen content propellants (LOCP) according to factors affecting combustion behavior such as oxidizer solid loading, particle size distribution, metal fuel additives and burning rate accelerator over metallic and non-metallic compositions.

The propellant formulations studied within this work represent the high and low smoke level compositions and were formulated on the basis of polybutadiene prepolymer (HTPB) as a binder and ammonium perchlorate (AP) as an oxidizer. Further investigation includes system in which metallic fuel [aluminum powder (Al)] was added at the expense of the binder. The role of burning rate accelerator [copper chromite $(\mathrm{CC})]$ in enhancing the burning rate was studied as well.

\section{EXPERIMENTAL}

The compositions of all tested propellant formulations are presented in Table 1. Preparation of the propellants for the test program was made by using a composite solid propellant mixer of capacity $1 \mathrm{Kg}$ provided with a degassing unit followed by propellant strands preparation using standard techniques. Propellant burning rates were measured by using a strand burner (Crawford bomb). Propellant strands, 100 $\mathrm{mm}$ length, $5 \mathrm{~mm}$ square cross-section, were burned under controlled nitrogen 
pressures and different temperatures. Burning rate was determined from the burning time of a specified propellant length $[1,5]$.

The propellant binder was composed of $85.7 \%$ HTPB as a main backbone, $12.3 \%$ HMDI as a cross-linking agent and $2.0 \%$ MAPO as a bonding agent [3, 4, 5]. All propellant compositions contained $0.5 \%$ carbon black (CB) as an opacifier which was found to be very important to apply the black body role [5]. The base line propellant formulation consisted of $45 \%$ AP $(9.0 \mu \mathrm{m})$ particles and the particle size variations were investigated through a bi-modal system with AP $(64.0 \mu \mathrm{m})$. The ballistic measurements were conducted at the pressure range from 1 bar to 100 bars and temperatures $-30,+20$ and $+50^{\circ} \mathrm{C}$.

The burning rate versus pressure law is expressed by the formula given by Saint Robert and Vieille:

$r=a \cdot P^{n}$

where:

$r$ : is the burning rate $(\mathrm{mm} / \mathrm{s})$;

a: is the burning rate pre-exponential factor $\left(\mathrm{mm} / \mathrm{s}\right.$. bar $\left.^{\mathrm{n}}\right)$;

$\mathrm{P}$ : is the combustion pressure (bar);

$\mathrm{n}$ : is the pressure exponent.

The factor (a) is known to be dependent on the propellant temperature and is defined by the empirical law:

$a=a_{0} \cdot e^{\left[\delta_{p}(T-T)\right]}$

where:

$\mathrm{a}$ : is the factor value at $\mathrm{T}$;

$\mathrm{a}_{0}$ : is the factor value at $\mathrm{T}_{0}$;

$\mathrm{T}$ : is the propellant temperature $(\mathrm{c})$;

$\mathrm{T}_{0}$ : is the propellant reference temperature $(\mathrm{c})$;

$\delta_{\mathrm{p}}$ : is the propellant temperature sensitivity of burning rate at assigned pressure $(/ \mathrm{c})$.

Table 1. The propellant formulations studied

\begin{tabular}{|l|c|c|c|c|c|c|c|c|c|c|}
\hline \multicolumn{1}{|c}{ Composition } & A1 & A2 & A3 & B2 & B3 & C2 & C3 & D2 & D3 & E1 \\
\hline Binder $\%$ & 74.5 & 64.5 & 54.5 & 54.5 & 54.5 & 44.5 & 34.5 & 51.5 & 48.5 & 38.5 \\
\hline AP $(9.0 \mu \mathrm{m}) \%$ & 25 & 35 & 45 & 30 & 15 & 45 & 45 & 45 & 45 & 45 \\
\hline AP $(64.0 \mu \mathrm{m}) \%$ & 0 & 0 & 0 & 15 & 30 & 0 & 0 & 0 & 0 & 0 \\
\hline AP average size $(\mu \mathrm{m})$ & 9.0 & 9.0 & 9.0 & 44.5 & 55.9 & 9.0 & 9.0 & 9.0 & 9.0 & 9.0 \\
\hline $\mathrm{Al}(11.5 \mu \mathrm{m}) \%$ & 0 & 0 & 0 & 0 & 0 & 10 & 20 & 0 & 0 & 10 \\
\hline $\mathrm{CC}(0.75 \mu \mathrm{m}) \%$ & 0 & 0 & 0 & 0 & 0 & 0 & 0 & 3 & 6 & 6 \\
\hline $\mathrm{CB}(10.0 \mu \mathrm{m}) \%$ & 0.5 & 0.5 & 0.5 & 0.5 & 0.5 & 0.5 & 0.5 & 0.5 & 0.5 & 0.5 \\
\hline
\end{tabular}




\section{RESULTS AND DISCUSION}

The effect of propellant formulations on the theoretical flame temperature was investigated at 70 bars by using a computer program of Gordon and McBride developed by NASA research center (1971) as shown in Fig.2 [6]. It is noted that all non-aluminized compositions containing 45\% AP have approximately the same low flame temperature, in the range from $1274 \mathrm{~K}$ to $1300 \mathrm{~K}$. CC as a burning rate accelerator has a negligible effect, about $2 \%$ maximum, on the flame temperature [1]. The increase of AP content from $25 \%$ to $45 \%$ causes an increase of about $7 \%$ in the flame temperature. A remarkable increase in the flame temperature results from the addition of aluminum in place of part of the polymeric binder. The temperature increase of propellant formulations containing $0 \%$ to $20 \%$ aluminum is of about $86 \%$.

\subsection{Flammability Limits}

Flammability of (LOCP) is a function of a number of parameters. For propellants consisting of the same ingredients, the basic flammability limit is presented in terms of pressure versus oxidizer content [7]. Fig.3 shows the flammability limits of propellants composed of an AP oxidizer of the smallest average particle size $(9.0$ $\mu \mathrm{m})$ used in this investigation. The results reveal a distinct limit between sustain and no-sustain combustion situations. Higher pressures are required for sustained combustion when decreasing the AP content [1]. While propellants containing $45 \%$ AP could sustain combustion even at pressures as low as 1 bar (the lowest tested pressure), propellants having 25\% AP did not burn even at 40 bars. Note that the non-burning compositions ignited but could not sustain combustion upon the removal of the ignition wire of the strand burner.

The flammability limit trend is hypothesized to be associated with the chemical reaction and heat feedback mechanisms [1]. Lower AP content propellants exhibit lower flame temperatures resulting in smaller heat transfer to the surface and possibly less extensive reactions, on the other hand, higher pressures cause the gasphase flame to be hotter, closer to the surface and more extensive [8]. As a result, the heat feedback to the propellant surface is enhanced and the combustion is more easily sustained [1].

Influence of the AP particle size was examined using propellants of the same composition (45\% AP, no additives) but with different AP particle size distribution of average volumetric sizes as follows: 9.0, 44.5 and $55.9 \mu \mathrm{m}$. Fig.4 presents the combustion limits in terms of the pressure versus average AP particle size at which the larger the particle size the higher the pressure required to sustain combustion. Formulations containing AP particles smaller than about $44 \mu \mathrm{m}$ could burn even at 10 bars pressure.

Decreasing the AP particle size in conventional composite propellants is known to increase the burning rate [9]. This behavior seems to indicate that, in general, smaller AP particles promote processes (heat transfer, diffusion) establishing more favorable conditions for sustained combustion [1]. 


\subsection{Ballistic Properties}

Effect of propellant composition and different additives on the burning rate level, in general, and on the burning rate dependence on pressure, in particular, was investigated at different temperatures.

The oxidizer content effect was studied using $9.0 \mu \mathrm{m}$ AP particles ranging from $25 \%$ to $45 \%$. Fig. 5 shows the trend of increasing the burning rate when increasing AP content. Similar behavior was observed in all pressures. The burning rates obtained were approximately tripled when increasing the AP content form $25 \%$ to $45 \%$ (e.g. from $0.53 \mathrm{~mm} / \mathrm{s}$ to $1.51 \mathrm{~mm} / \mathrm{s}$, respectively, for a pressure of 70 bars). A similar pressure exponent (n) (between 0.11 and 0.34 ) for the various AP content levels was verified. Fig. 6 shows the burning rate versus pressure correlations for different AP content. The increase in the burning rate when increasing the oxidizer content was demonstrated in all pressures due to the increase of the oxidizer volumetric solid loading through the propellant microstructure, the increase of the reaction ability to be exothermic and the increase of the propellant surface temperature over the solid gas interface [4, 9].

The oxidizer particle size distribution effect on the burning rate is shown in Fig.7 for propellants containing 45\% AP of average particle sizes ranging from $9.0 \mu \mathrm{m}$ to 56.0 $\mu \mathrm{m}$. In general, a monotonic decrease in the burning rate when increasing the particle size was demonstrated in all pressures due to the decrease of the oxidizer burning surface area [1]. Fig.8 shows the burning rate versus pressure correlations for different AP particle sizes. The variation of the pressure exponent with the AP particle size as obtained in the tests were shown in Fig.9 where the values of $n$ decreased from about 0.34 to 0.28 for particle size range from approximately $9.0 \mu \mathrm{m}$ to $45.0 \mu \mathrm{m}$ respectively and then increased to about 0.31 for particle size of approximately $56.0 \mu \mathrm{m}$. This behavior may be interpreted in terms of propellant combustion mechanism and the decomposition kinetics of AP [9].

The addition of aluminum $(11.5 \mu \mathrm{m})$ to the propellant formulation at the expense of the polymeric binder was found to have a remarkable effect on the burning rate as shown in Fig.10, where the effect is similar in all pressure values, revealing a monotonic increase with the aluminum fractions ranged from $10 \%$ to $20 \%$ compared to the corresponding burning rates obtained for non-aluminized propellants. All tests of the aluminized formulations were performed with $45 \%$ AP of $9.0 \mu \mathrm{m}$ average particle sizes. The aluminized propellant burning rates were less sensitive to pressure. Values of $\mathrm{n}$ decreased from 0.34 for $0 \% \mathrm{Al}$ to approximately 0.12 for $20 \%$ Al [Fig.11] which is a known phenomenon for conventional solid propellants [9, 10]. However, typically burning rates are not much affected by presence of aluminum in conventional propellants. The significant burning rate increase due to aluminum in (LOCP) may be attributed to its influence on the flame temperature, heat transfer and burning rate mechanisms. The relative increase in the temperature-difference between the flame and the propellant surface, representing the driving force for the conductive-convective heat transfer, is much larger in (LOCP) than in conventional propellants. In addiction, the relative contribution of the heat transfer radiation seems to be significantly greater for (LOCP), as the flame around each individual aluminum particle attains a very high temperature, even if the overall mixture is (LOCP). It 
should be noted that the aluminum, while in conventional propellants is added at the expense of the oxidizer, in (LOCP) replaces part of the fuel binder [1,10].

The effect of burning rate accelerator $\mathrm{CC}$, with average particle size of less than 1 $\mu \mathrm{m}$, was investigated. The accelerator at fractions varying from $3.0 \%$ to $6.0 \%$ was added to propellant formulations containing $45 \%$ AP oxidizer at the expense of the polymeric binder. The $0.75 \mu \mathrm{m}$ particle size copper chromite burning rate accelerator exhibited a moderate increase in burning rate for the non-aluminized propellants [Fig.12], due to the exothermic reaction at the CC-AP interface which lowers the oxidizer ignition temperature, increase its sensitivity to heat, reduces the activation energy required to start the deflagration reaction on the propellant surface and consequently increase the reaction rate through the propellant solid-gas interface [11]. The copper chromite burning rate accelerator exhibited a sharp increase in the burning rate magnitude when changing from non-aluminized to aluminized formulations [Fig.13], due to the additional effect, mentioned before, of $10.0 \% \mathrm{Al}-$ powder. The values of pressure exponent are increased by about $23.0 \%$ when changing $\mathrm{CC} \%$ from 3.0 to 6.0 in the non-aluminized formulations. When comparing the addition of $6.0 \%$ CC over non-aluminized and aluminized formulations $\mathrm{n}$ was decreased from about 0.34 to 0.28 for the first one and increased from about 0.16 to 0.2 for the second. It is clear that the effect of burning rate accelerator is not the same for the aluminized and the non-aluminized (LOCP).

The effect of propellant formulations and different additives on the burning rate at different temperatures was investigated through the parameter called propellant temperature sensitivity factor of burning rate at assigned pressure $\left(\delta_{p}\right)$ as shown in Fig.14. The sensitivity factor was decreased with increasing the oxidizer solid loading and increased with increasing the oxidizer particle size. The sensitivity factor of the aluminized and non-aluminized formulations was reduced by the addition of the burning rate accelerator CC. A significant decrease for the sensitivity factor was verified due to the incorporation of Al-powder instead of a part of the binder, but for the conventional propellants the behavior is opposite because of the addition of Alpowder instead of a part of the oxidizer [12].

\section{CONCLUSION}

Combustion envelope of AP/HTPB-based low oxygen content composite solid propellants was found to be broader for higher pressures, larger AP contents and smaller AP particle size. Capability of sustaining combustion was increased when fine AP sizes of about 9.0 micrometers and solid loading of about $45.0 \%$ used even at atmospheric pressure.

Burning rate enhancement was demonstrated for higher AP content, smaller AP particle size, the use of copper chromite as a burning rate accelerator and, most remarkably, the addition of aluminum powder to the propellant formulations.

The role of lowering the burning rate pressure exponent and the propellant temperature sensitivity factor of burning rate at assigned pressure was, remarkably, verified for higher aluminum powder contents within the same AP solid loading. Low pressure exponent do not necessarily imply low temperature sensitivity $\left(\delta_{p}\right)$. 
The effect of pressure and temperature on the sensitivity factor $\left(\delta_{p}\right)$ is very complex and the additives appear to provide a most effective way of reducing the value of the sensitivity factor. The theoretical predictions of the sensitivity factor are very complicated and must be dependent on real experimental results.

\section{REFERENCES}

[1] Abraham Shalom, Alon Gany, "Flammability Limits and Ballistic Properties of Fuel-Rich Propellants", Propellants, Explosives, Pyrotechnics 16, pp 59-64 (1991).

[2] Box, et al., "Turbine Engine with Solid Fuel Starter", United States Patent 6,374,592, April (2002).

[3] Brown, et al., "Manufacture of Propellant Compositions and Propellant Charges", United States Patent 6,036,894, March (2000).

[4] Alain Davenas, "Solid Rocket Propulsion Technology", Pergamon Press, N.Y., chapter 12 (1993).

[5] Alain Davenas, "Solid Rocket Propulsion Technology", Pergamon Press, N.Y., chapter 10 (1993).

[6] S. Gordon, B. J. McBride, "Computer Program for Calculation of Complex Chemical Equilibrium Compositions", NASA report SP 273 (1971).

[7] Alice L. Atwood, Cannon F. Price, Thomas L. Boggs, "Ignitability Measurements of Solid Propellants", ICT conference, PP 44-1 to 44-15 (1989).

[8] H. F. R. Schoyer, P. A. O. G. Karting, "Low Pressure Combustion of Composite Propellants", Propellants, Explosives, Pyrotechnics 9, PP 149-156 (1984).

[9] M. S. Patil, "Ballistic and Mechanical Properties of HTPB-Based Composite propellants", J. of Hazards Materials 19, PP 271-278 (1988).

[10] M. Q. Brewster, "Influence of Metal Agglomeration and Heat feedback on Composite Propellant Burning Rate", J. of Propulsion, vol.7, No.6, Nov.-Dec. (1991).

[11] S. Krishnan, R. Jeenu, "Combustion Characteristics of AP/ HTPB Propellants with Burning Rate Modifiers", J. of Propulsion and Powder, vol.8, No.4, July (1992).

[12] S. Miyazaki, "Temperature Sensitivity of Burning Rate of Ammonium Perchlorate Propellants", Aeronautical and Space Division, Nissan motor co., (1987). 


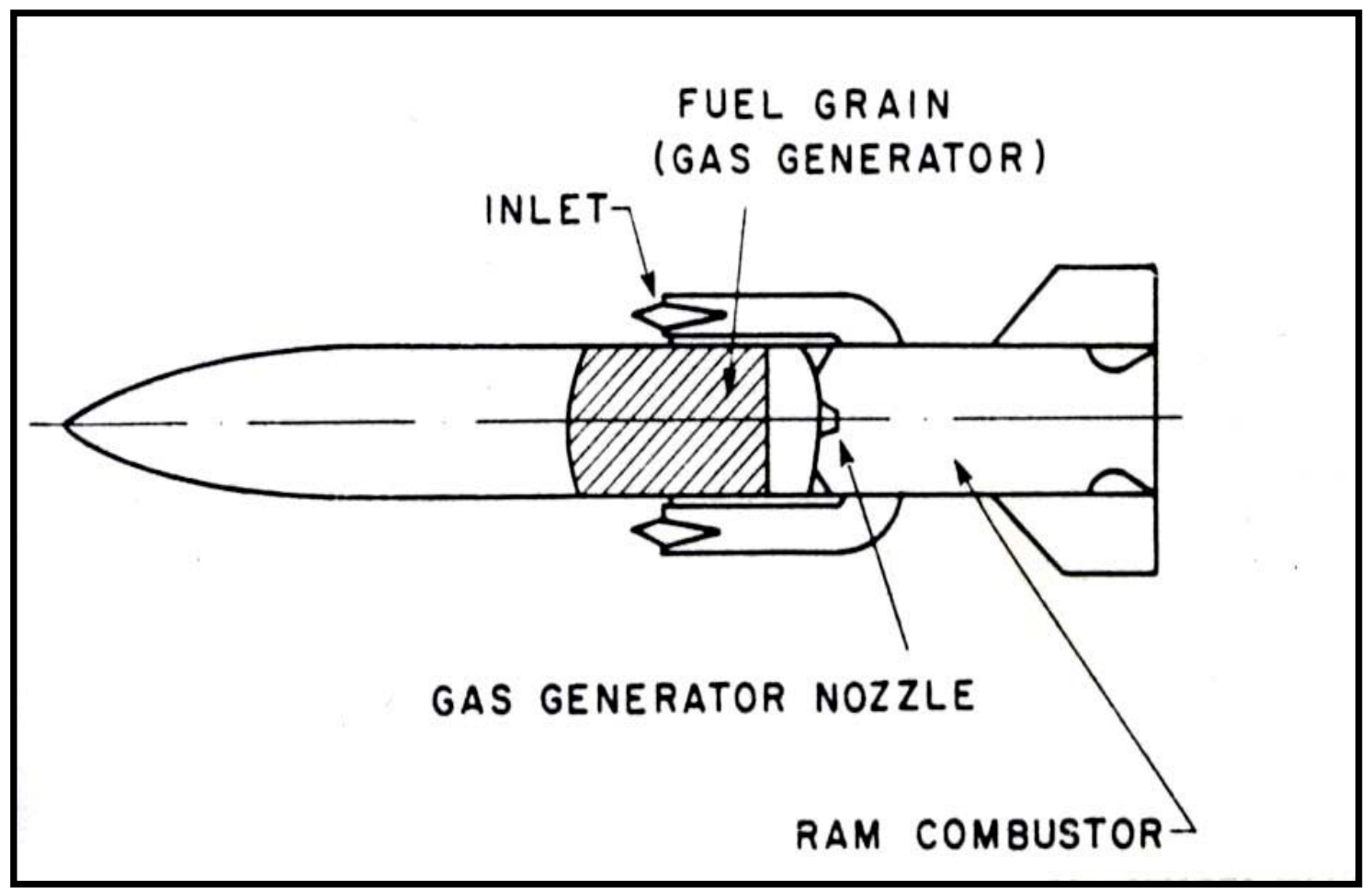

Fig.1. Schematic diagram for a typical solid fuel ramjet.

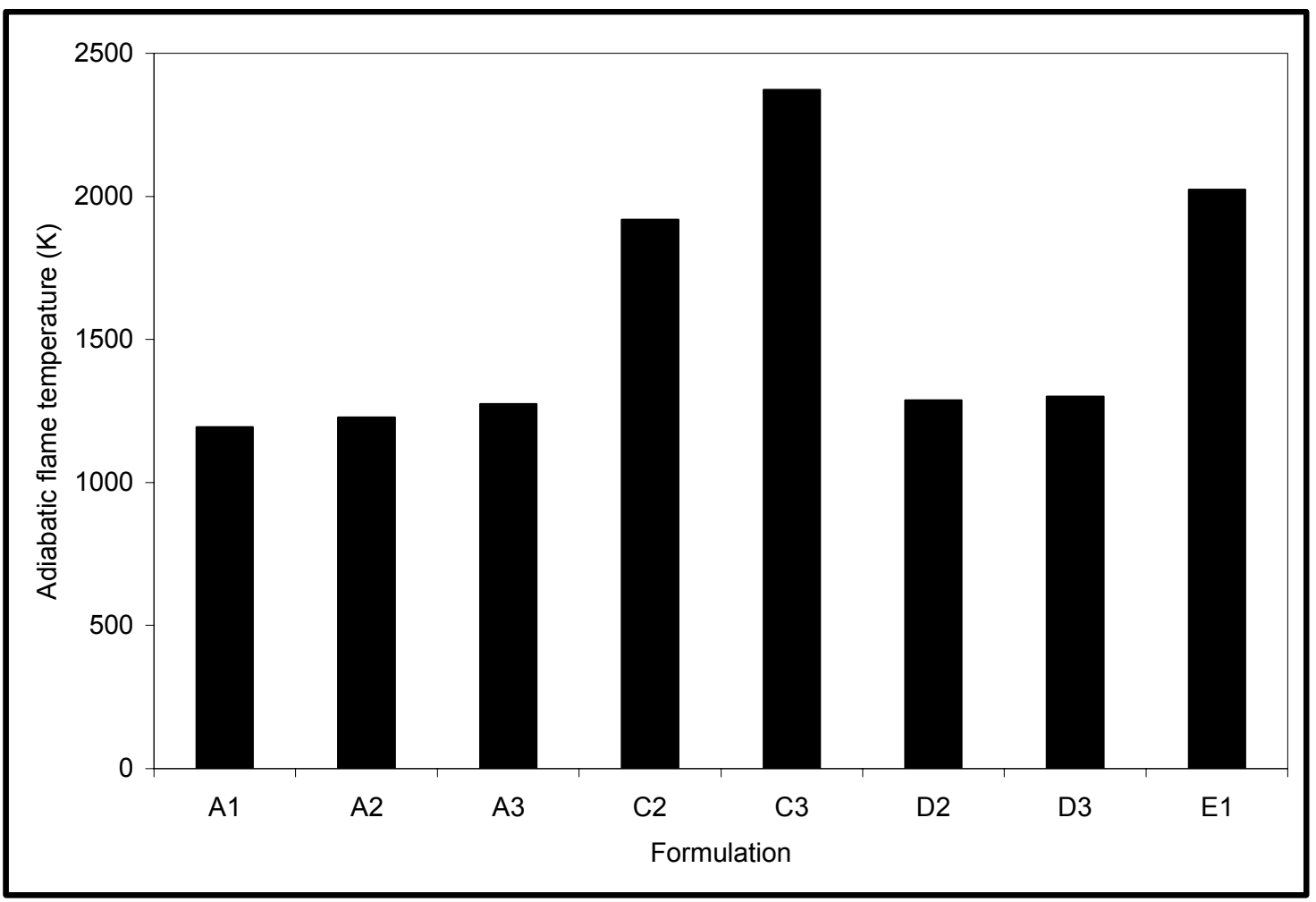

Fig.2. Effect of propellant formulations on the adiabaic flame temperature at 70 bars. 


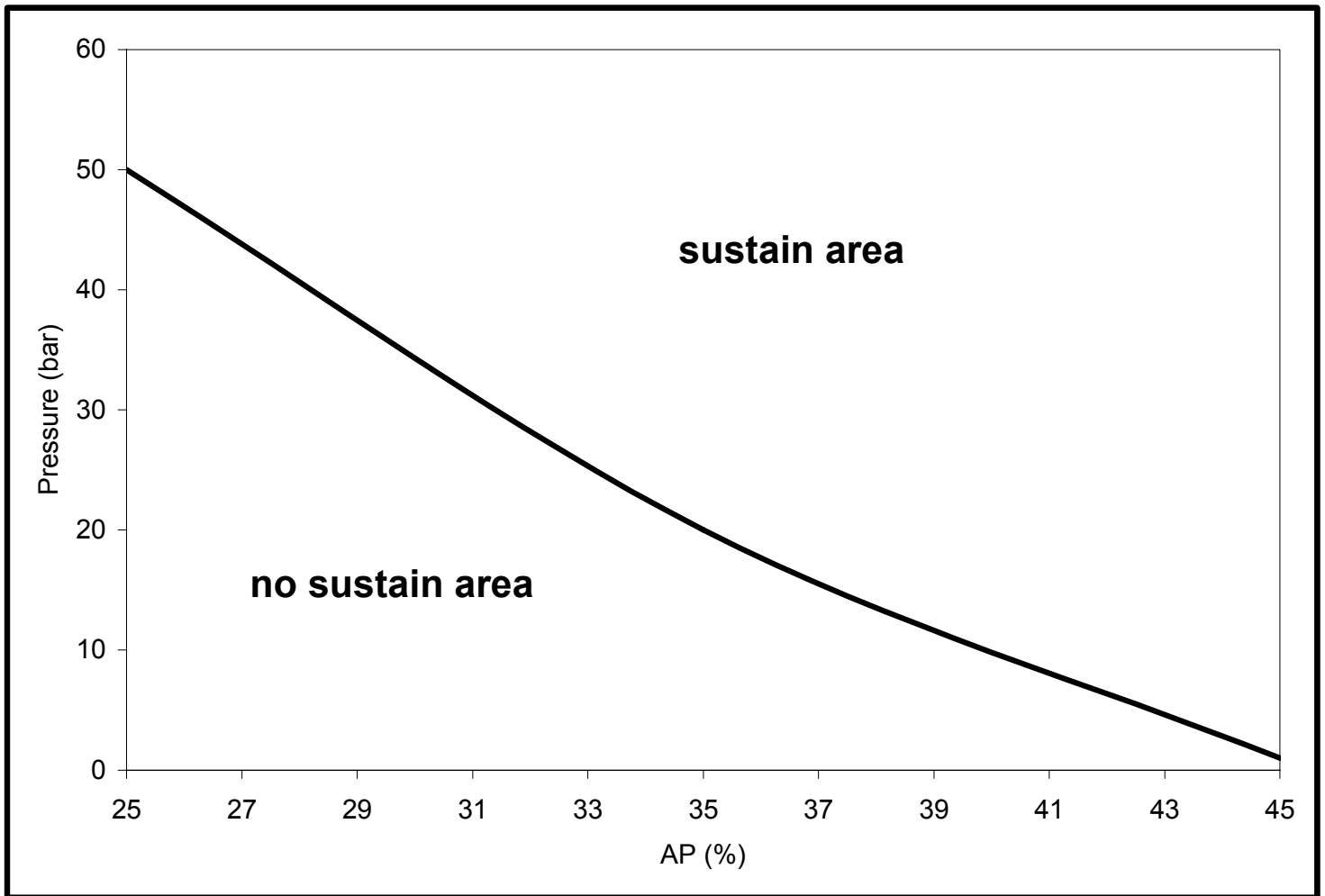

Fig.3. Effect of oxidizer solid loading on the propellant flammability limits.

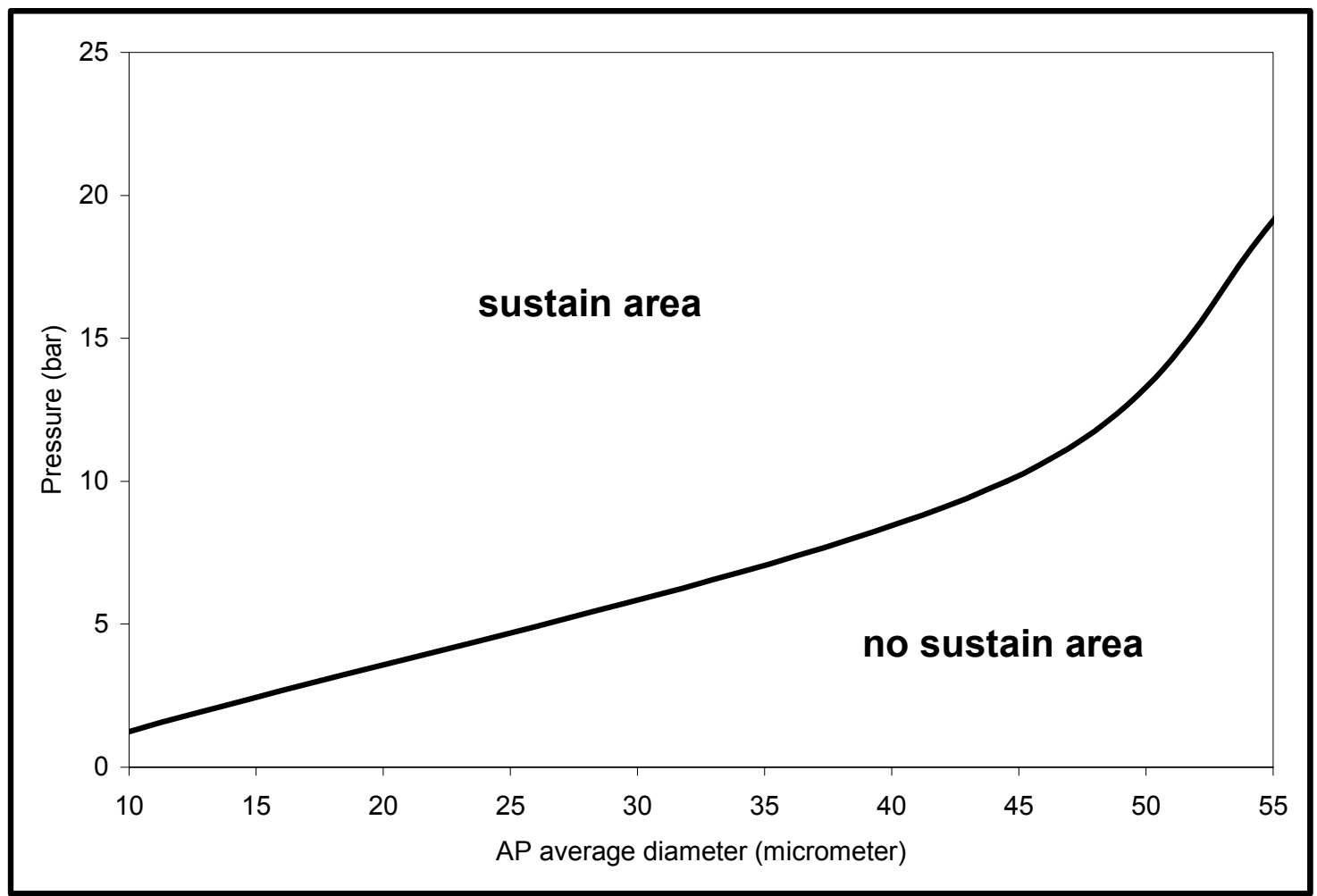

Fig.4. Effect of oxidizer particle size on the propellant flammability limits. 


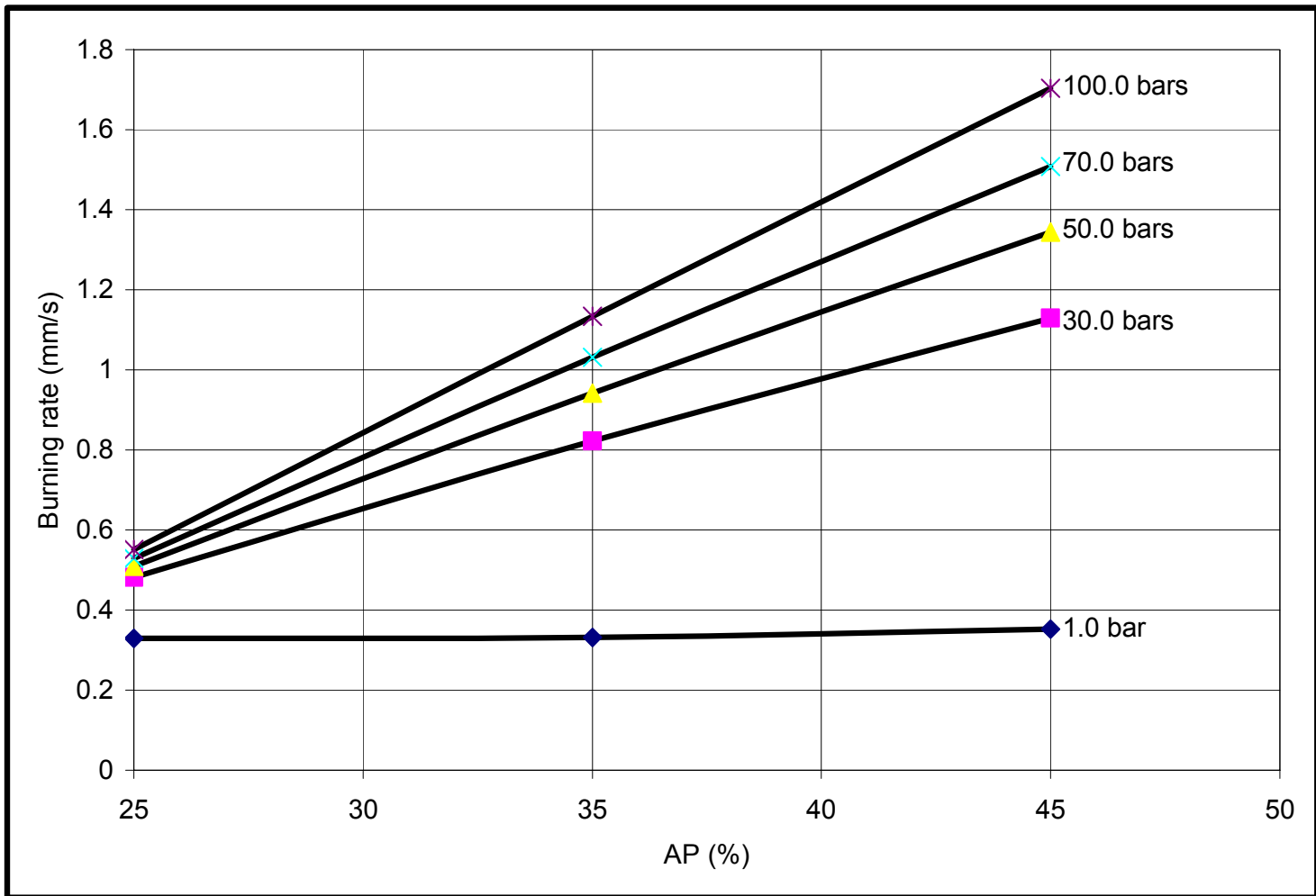

Fig.5. Effect of the oxidizer solid loading on the burning rate.

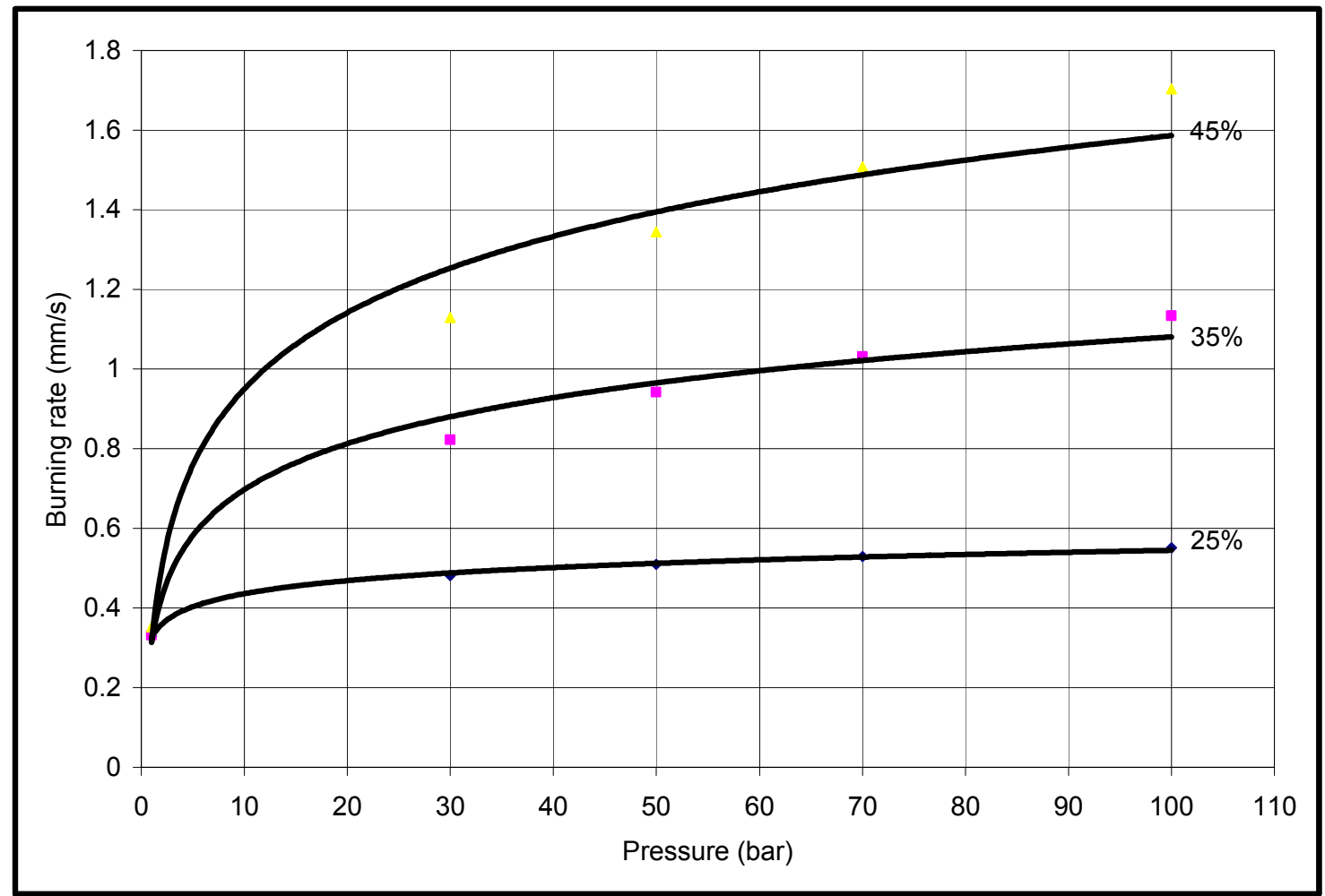

Fig.6. Burning rate versus pressure at different AP contents. 


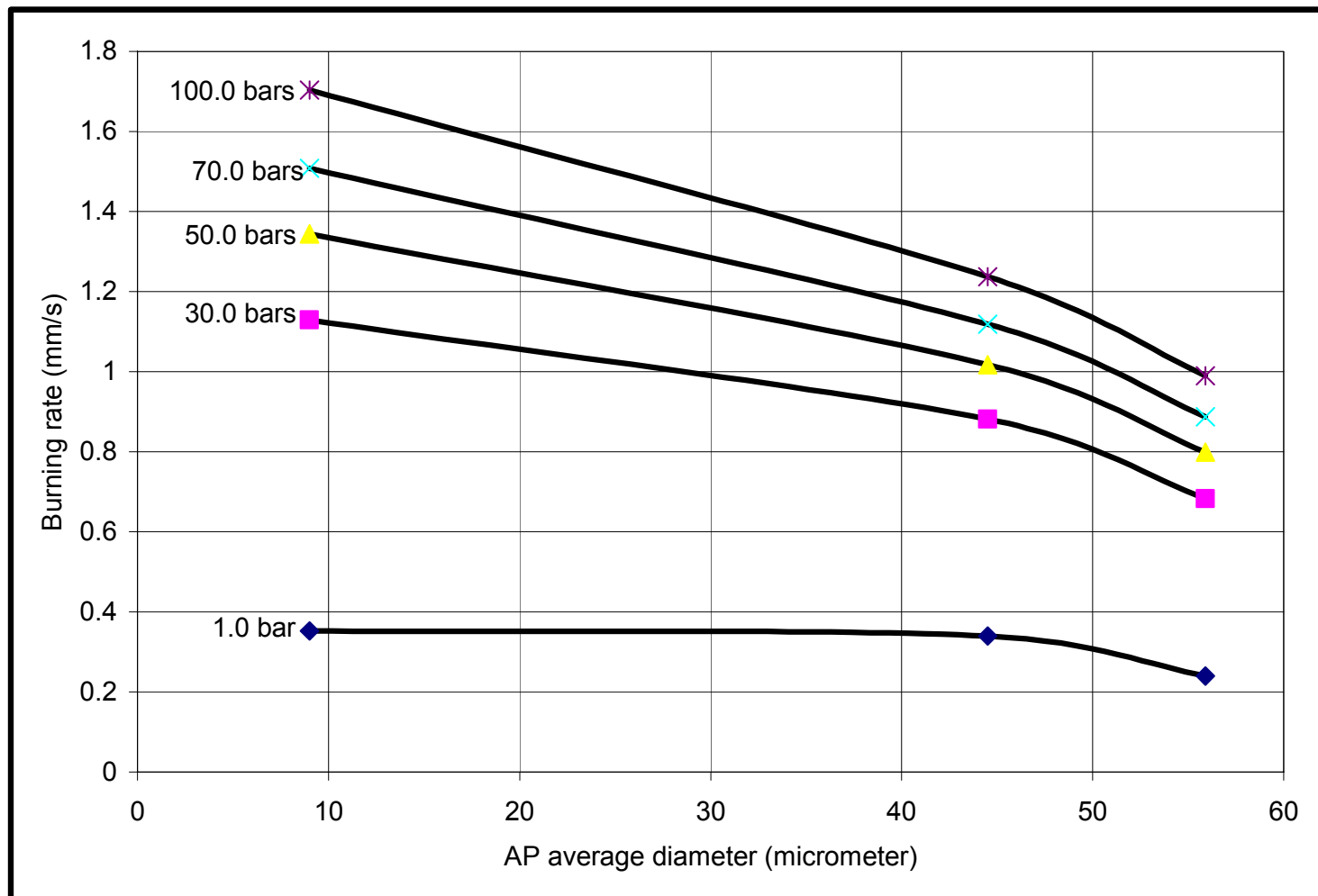

Fig.7. Effect of the oxidizer particle size on the burning rate.

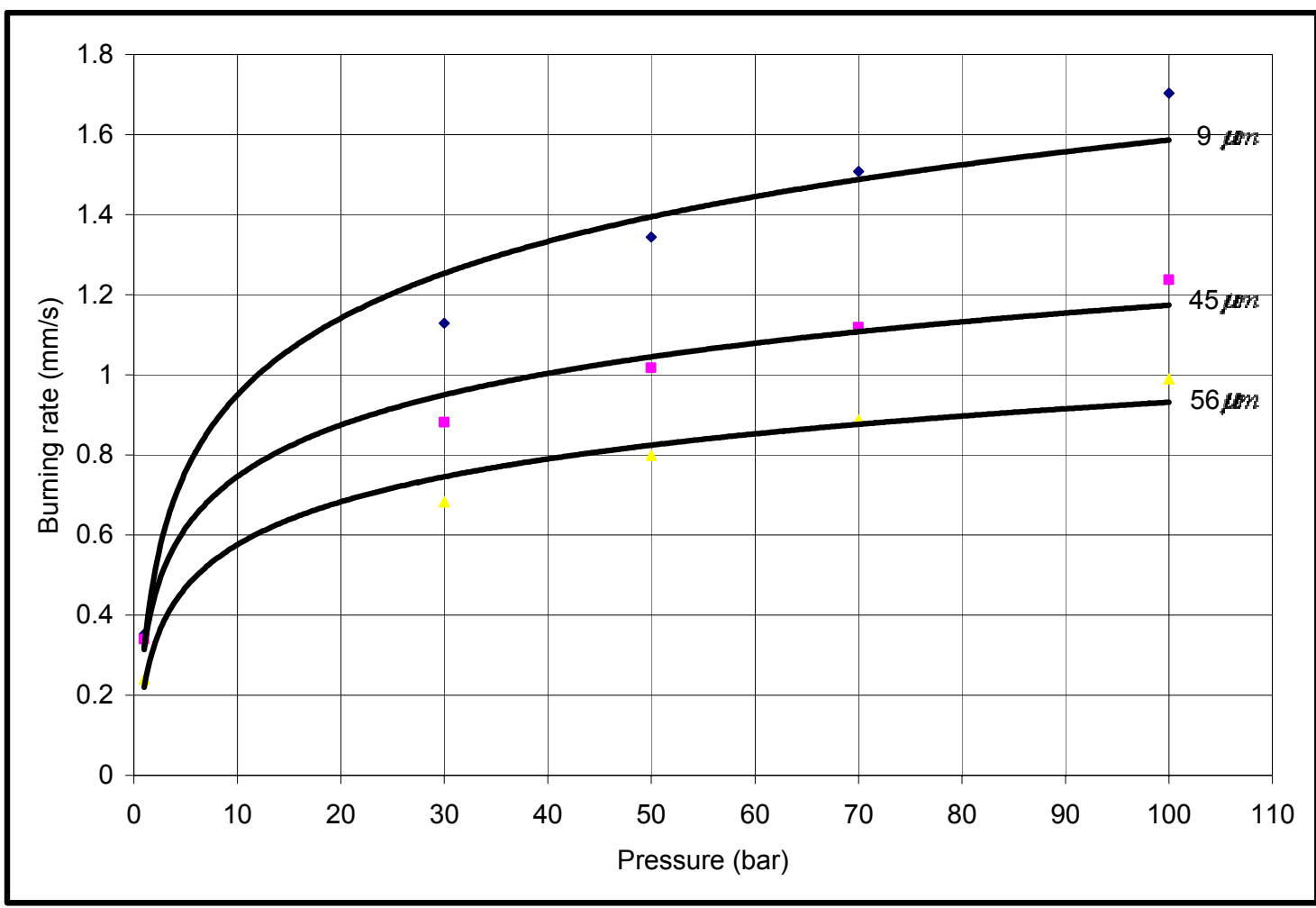

Fig.8. Burning rate versus pressure at different AP particle sizes. 


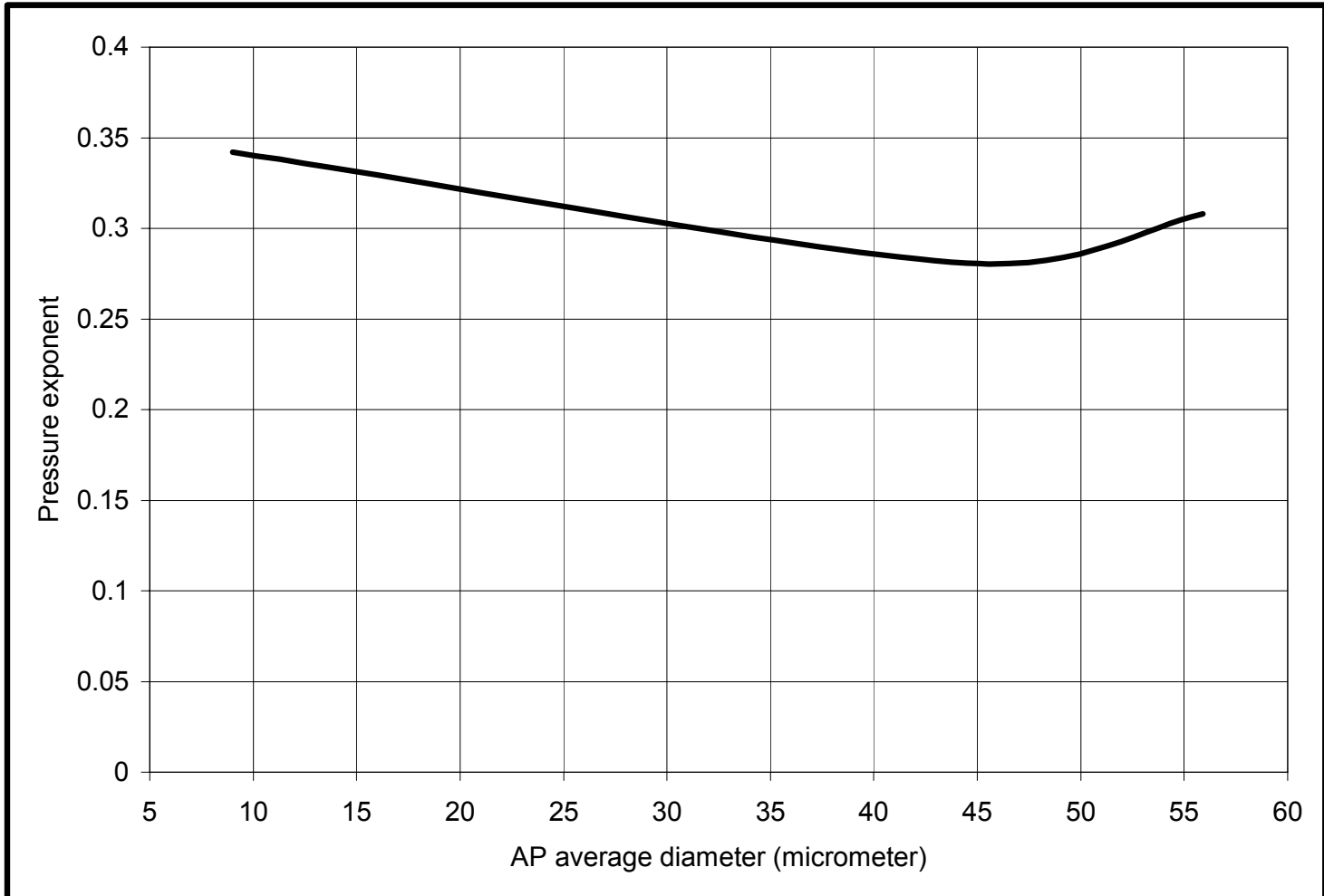

Fig.9. Effect of AP particle size on the pressure exponent.

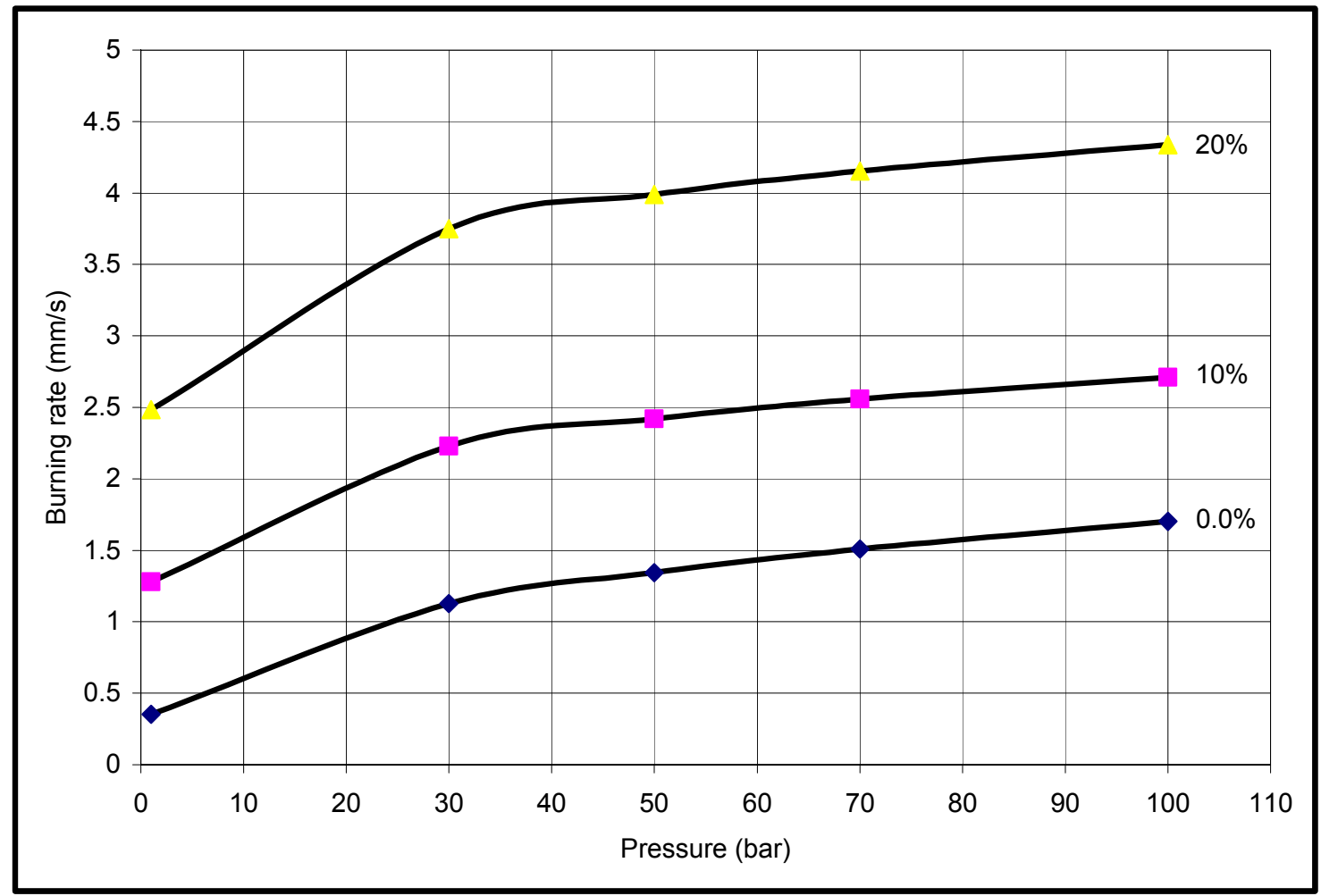

Fig.10. Burning rate versus pressure at different $\mathrm{Al}$ contents. 


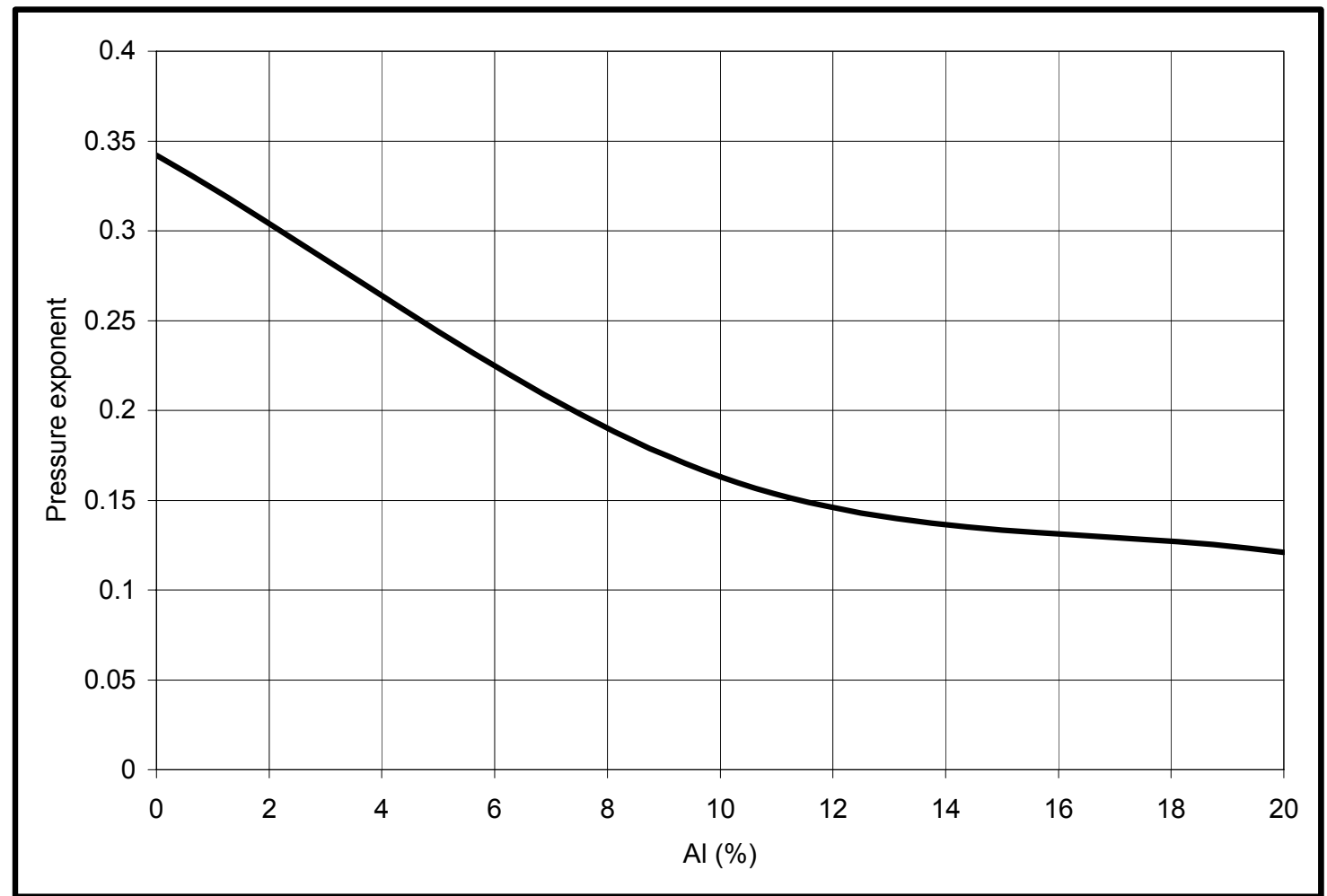

Fig.11. Effect of Al content on the pressure exponent.

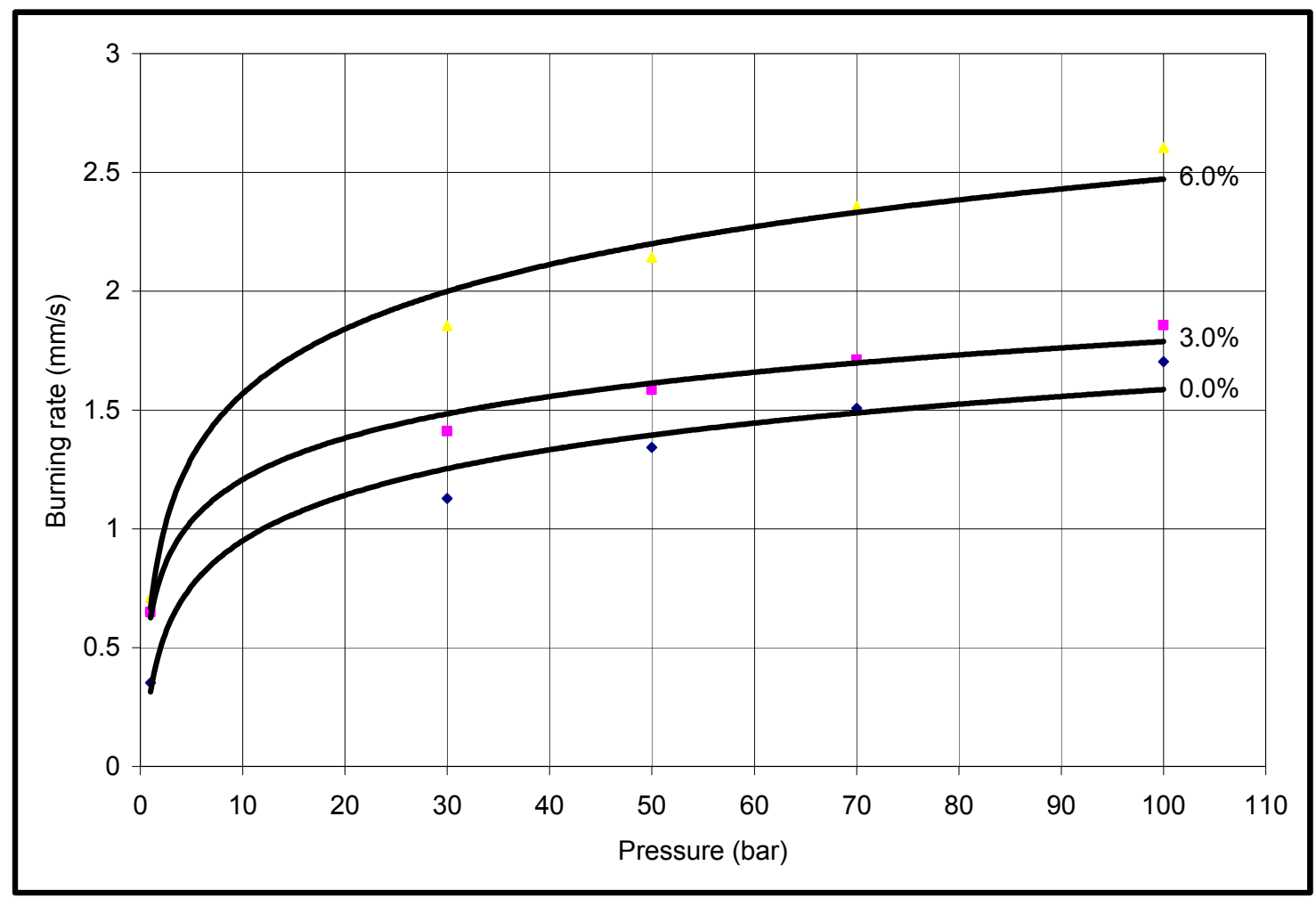

Fig.12. Burning rate versus pressure at different CC content for the non-aluminized formulations. 


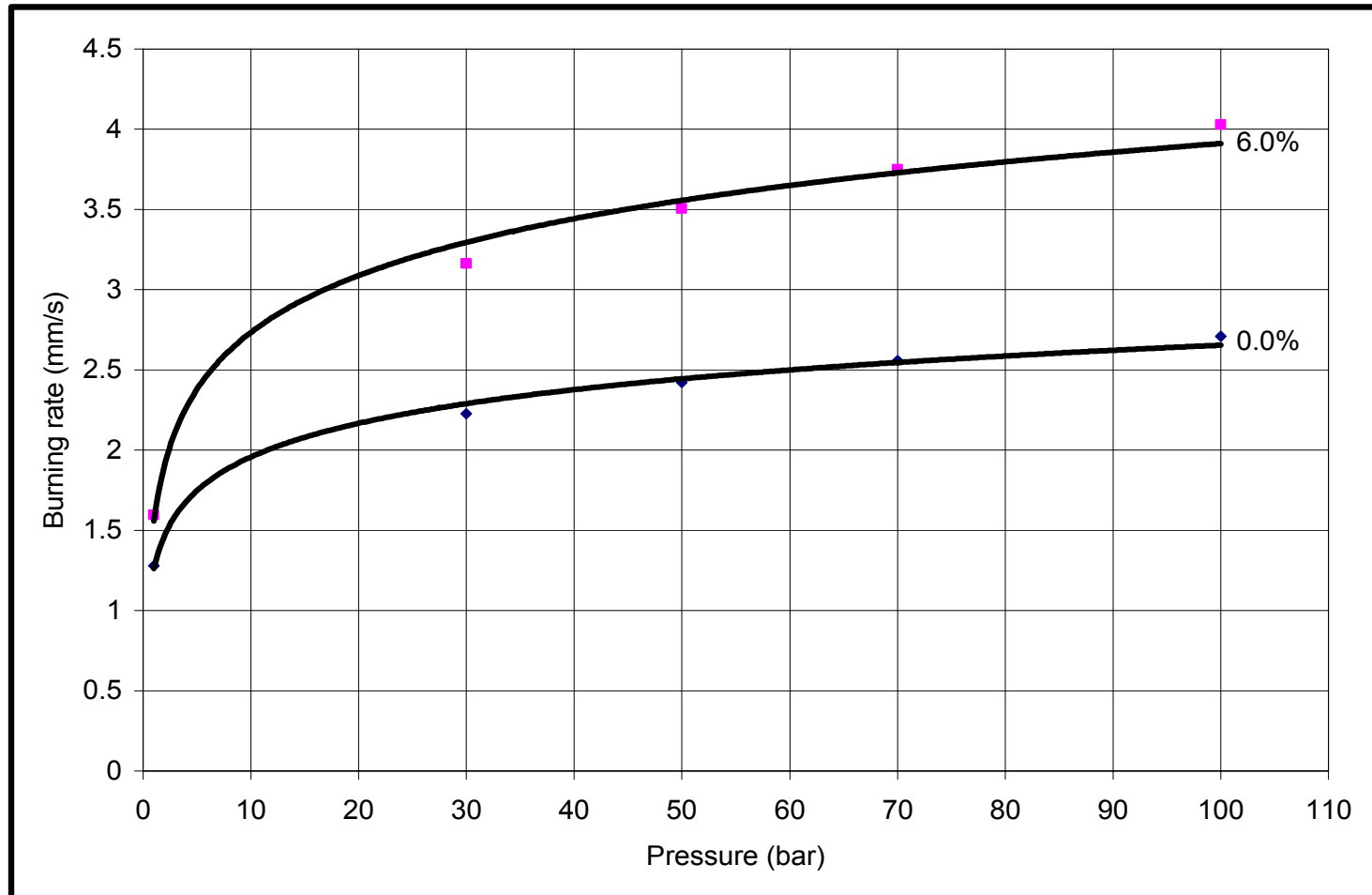

Fig.13. Burning rate versus pressure at different CC content for the aluminized formulations.

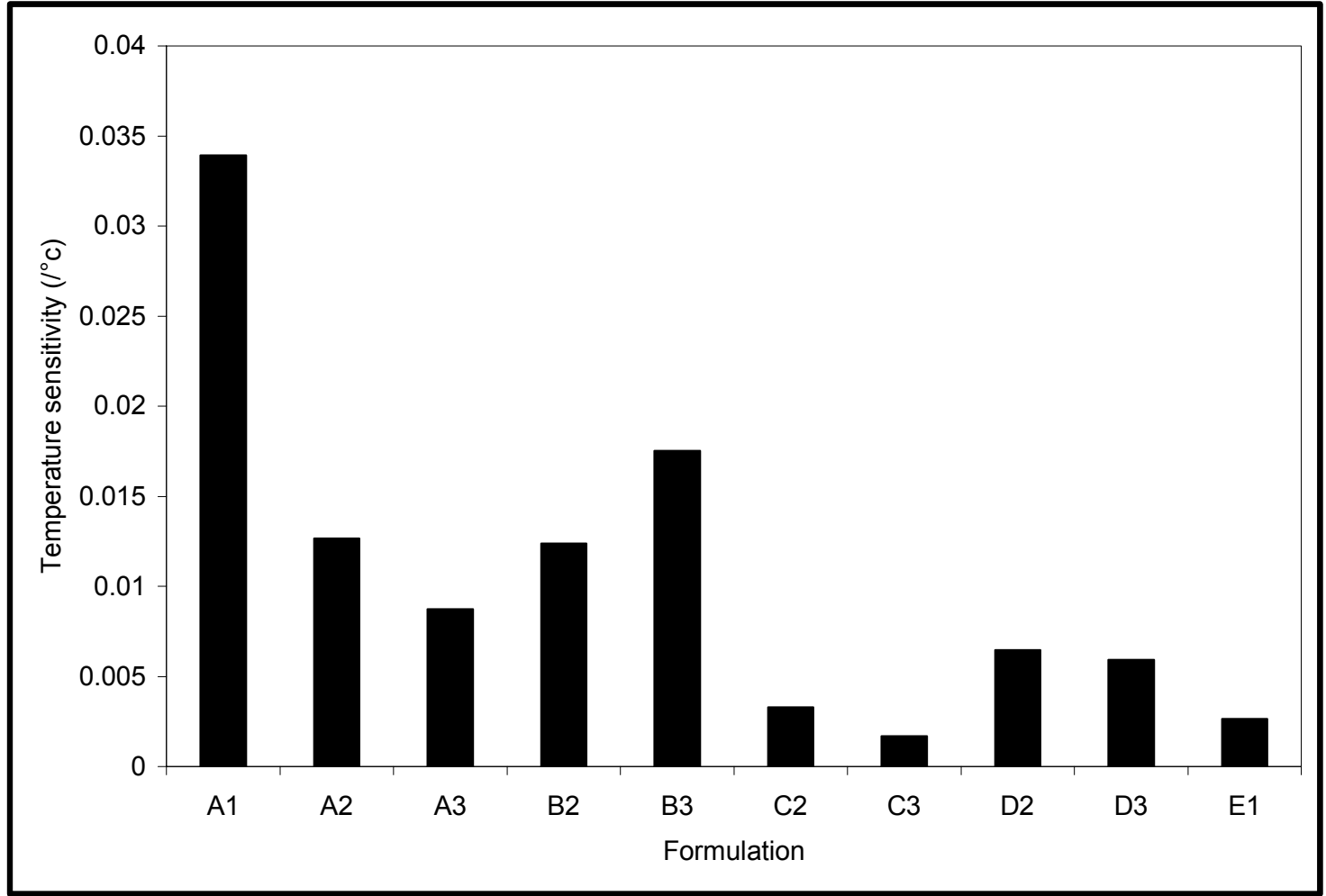

Fig.14. Effect of propellant formulations on the temperature sensitivity of burning rate at assigned pressure. 